\title{
Student views on continuous assessment at Birmingham University Medical School
}

\author{
J K CRUICKSHANK, P W BARRITT, F MCBESAG, N WATERHOUSE, L H GOLDMAN
}

British Medical fournal, 1975, 4, 265-267

\section{Summary}

Student opinion on the system of continuous assessment used at Birmingham Medical School was sampled by distributing questionnaires to 621 students in the first four years of the course; 482 questionnaires $(\mathbf{7 8} \%$ ) were returned. Many comments and criticisms of the system were received but the vast majority of students $(92 \%)$ said they preferred the present style of assessment to conventional final examinations. These criticisms are discussed and recommendations are made to improve the existing scheme.

\section{Introduction}

Since 1966 Birmingham University Medical School has operated a system of continuous assessment, which has replaced conventional 2nd $\mathrm{MB}$ and final examinations. Trethowan has described the type, timing, and methods of assessment in use up to $1970^{1}$ and more recently. ${ }^{2}$ There are about 60 assessments throughout the five-year course; these include written examinations (of multiple choice (MC) question, short answer, or essay type), viva voces, essay and project work, case histories, and personal

Education Subcommittee, University of Birmingham Medical Society, Birmingham B15 2TJ

J K CRUICKSHANK, BSC final-year student representative (now MB, CHB, house physician, Dudley Road Hospital, Birmingham B18 7QH)

P W BARRITT, fifth-year student representative

F MCBESAG, PH D, fourth-year student representative

$\mathrm{N}$ WATERHOUSE, third-year student representative

L H GOLDMAN, BA, second-year student representative assessments by tutors and chiefs of clinical firms. The course itself is still basically traditional though at present under review. The final year consists of rotating 10-week periods in medicine, surgery, psychiatry, obstetrics and gynaecology, and paediatrics (combined with subspecialities and general practice). Students are assessed throughout each period and, taking account of their previous years' marks in the subject, are given a final grade. There are no final exams at the end of the year, except for those whose performance is found to be unsatisfactory or who are invited for possible honours awards.

We reviewed students' opinions of the system at Birmingham, and our findings may be useful to other schools contemplating similar schemes.

\section{Method}

The survey was conducted in February 1975, when questionnaires were distributed to the 621 students in the first four years of the course; $482(78 \%)$ were completed and returned. It proved impracticable to circulate questionnaires to the scattered final year students.

The questionnaire contained 16 single questions of the yes/no type and one more detailed one on types of examination and all students were asked to answer all except the last three, which were for clinical students only. Space was provided for any further comments about the assessment system to make up for faults in the questionnaire's design. The discussion reflects as many of the students' comments as possible but the overall view is our collective responsibility.

\section{Results}

A breakdown of the answers to the questions asked is given in the table, taking the 482 replies as $100^{\circ}$. Not all respondents answered all questions. When significant variation occurred between years the results are given in full, broken down by year. One question, not shown in the table, asked in more detail what type, or combination of types, of examination most thoroughly tested a "true understanding of the subject." The variations offered were: MC questions and short 
Answers given by students to questions. Results are percentages and are given for separate years when these results differed appreciably from overall response

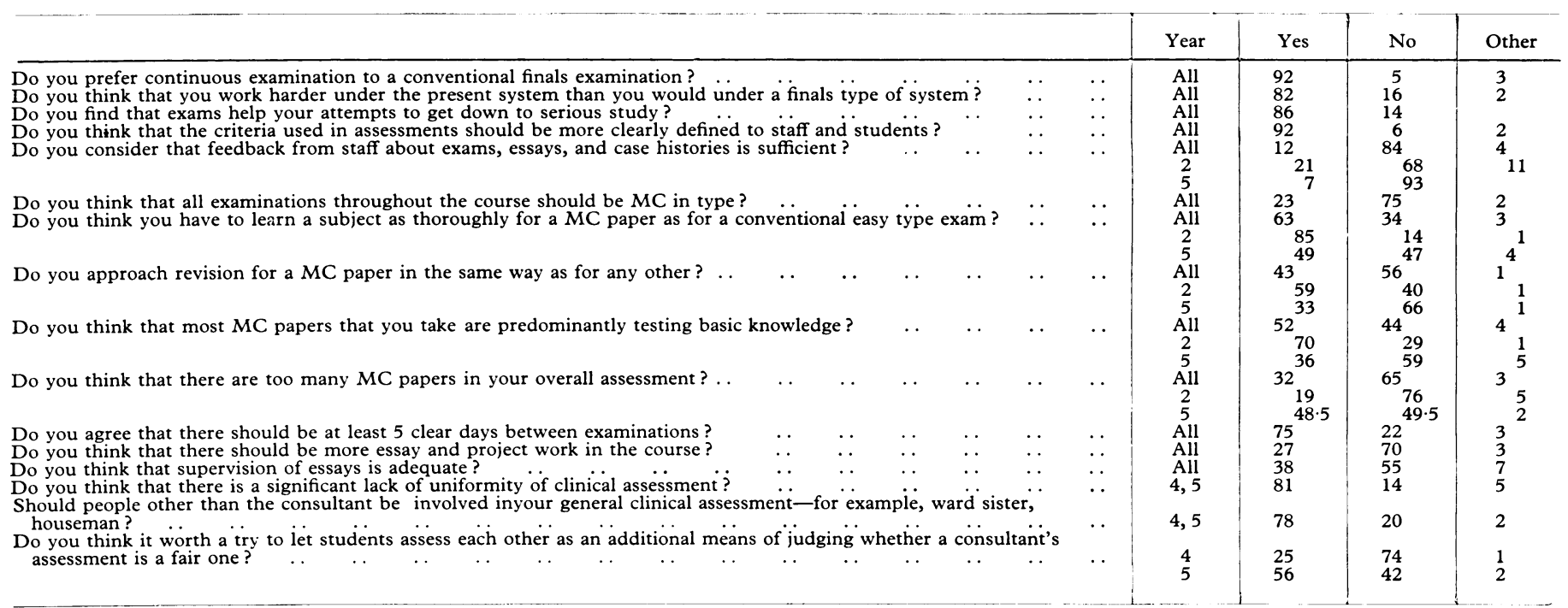

answers $(39 \%)$; MC questions, essays, and short answers $(29 \%)$; short answers $(7 \%)$; MC questions $(6 \%)$; viva voces $(6 \%)$; essays $(3 \%)$; and other combinations $(9 \%)$.

General reactions-The answer to the first question indicated clearly that the vast majority of students in all years $(92 \%)$ preferred a continuous examination system to conventional final exams. Most students also thought that they worked harder under the present scheme than they would have done with final exams and $86 \%$ found that examinations helped their attempts to study seriously. Many students commented that Birmingham relied too heavily on formal examination and not enough on other types of assessment. They felt work often became too exam-oriented and that this limited initiative, the need and opportunity for wider reading, and the time available for other university activities. Some students complained that continuous assessment put them under a perpetual strain.

Feedback from staff-Only $12 \%$ of students were satisfied with feedback from staff, the percentage falling appreciably from $21 \%$ in year 2 to only $7 \%$ in year 5 .

Format of written exams-Attitudes to MC papers changed with increasing experience of them. The percentage of students who thought that they did not have to learn a subject as thoroughly for MC questions as for an essay-type exam rose from $14^{\circ}$ in year 2 to $47 \%$ in year 5 . In year $270 \%$ thought that most of the MC exams were predominantly testing basic knowledge, but in year 5 this figure had fallen to $36 \%$. Comments from students indicated that MC examinations often dweic on more obscure and less important aspects of a subject. The knowledge that the answer was somewhere staring at the candidate reassured some, and the absence of time limits in many MC papers was generally popular. Nevertheless, the proportion of students who felt that there were too many $\mathrm{MC}$ papers in the course rose from $19 \%$ in year 2 to nearly $50 \%$ by year 5 . Some felt that MC examinations were favoured by staff because of the relative ease of marking.

Pass/fail divisions-There were strong feelings in all years about the location of pass/fail divisions. There was a widespread feeling that some departments were using Gaussian distributions to decide on the number of students to be given different grades. Students believed that failure should result when a satisfactory standard had not been achieved and not when their marks lay more than one standard deviation from the mean.

Project work-Only $27 \%$ of students favoured more essay and project work in the course, though comments suggested that the question was badly worded since more would have been in favour of substituting projects and essays for assessment currently by means of written exams. Many students found writing essays a good way of synthesising their knowledge of a subject.

Exam timing-The timing of the many examinations in the course was a vexing problem. Students complained that exams were often bunched together, thus interfering with good performance and other continuing work, particularly on the wards. Similarly, staff complained of poor attendance on the wards and in the lecture theatre when major examinations were imminent. We found that $75 \%$ of students would prefer to have at least five clear days between major examinations.
Clinical assessments-Altogether $81 \%$ of students felt that there was a significant lack of uniformity in their ward assessments, and $92 \%$ thought that the criteria used in assessments should be more clearly defined to staff and students, particularly those used in the consultant's personal gradings. Nearly $80 \%$ approved of involving the houseman and ward sister in their assessment, as they felt that these members of staff were better able to judge a student's day-to-day ward work in areas like attendance, attitude to patients, and willingness to help with routine duties, such as venepuncture. A suggestion that students should assess one another as an additional criterion to be used in contentious cases did not meet with much enthusiasm in year 4 , but in year $556 \%$ thought that it might be worth a try. Those against the idea feared it would lead to favouritism and bitterness among contemporaries, though several said it was easier to fool a chief than a colleague.

\section{SUMMARY OF CRITICISMS}

The general criticisms that students had of the current scheme of continuous assessment may be summarised as follows: (a) overemphasis on formal examination-intermittent examination rather than continuous assessment; (b) excessive use of pure $\mathrm{MC}$ format ; $(b)$ unfair location of pass/fail border; $(d)$ inadequate feedback, which was received too slowly after assessment; $(e)$ bad examination timing; $(f)$ unclear definition of criteria for assessments; $(g)$ subjectiveness of the clinical assessments made by consultants alone.

\section{Discussion}

One of the major problems of continuous assessment is that students have become much more conscious of impending examinations, and some students (and many of the staff) feel that this turns into an obsession that limits initiative and real interest in a subject. Attendance at courses that are not examinable is usually poor. This is a serious shortcoming of the system that we hope our suggestions might improve.

\section{CORE KNOWLEDGE}

Failure should result only if the student has shown inadequate understanding of the basic essentials of a subject. We would like to see examinations containing a core of questions on basic vital knowledge in which students have to attain a very high mark to pass. Further less crucial questions on more esoteric aspects could be used to distinguish excellent, good, and satisfactory grades. The difficulty lies in reaching agreement with the departments concerned over what constitutes essential 
knowledge in their subject. The core should be based on what is considered essential knowledge for a future doctor, and both hospital and community doctors may be able to help departments greatly in defining this fundamental core. Once agreed on, the core could be clearly and explicitly defined to students, perhaps in the form of course objectives. If such a system was introduced $100 \%$ of students might pass many of the examinations, a state of affairs which we would find quite acceptable. Not only might the present preoccupation with examinations be reduced but the learning and understanding of essential subject matter might also improve.

\section{FEWER EXAMINATIONS, MORE FEEDBACK}

The system would also benefit if it were to be more continuous, with less dependence on written exams and more on essay, project, and tutorial work. In two departments, physiology and pathology, small-group teaching is already used extensively and seems to work well. The role of the tutor might be extended to include organising small tests and marking essays.

The use of MC tests has become excessive, and they should be replaced by examinations using various types of question. This would be fairer to those students who have particular difficulty with a MC format and might avoid producing doctors whose only mode of expression consists of pencilling in squares on computer cards. The problems of examination timing could be improved by leaving five days between major examinations. If lectures covering old ground are to be given they should occur near the time of the examinations so that new material is not presented immediately before examinations. MC papers were considered particularly useful for testing wide-ranging factual knowledge, whereas short answers and essays were more suited to testing an understanding of general principles.

The need for greater and faster feedback from staff was emphasised in the results. Students felt strongly that the full educational potential of their efforts was not being achieved due to the demoralising lack of comment on many returned essays and case histories. Opportunities for students to go through MC questions and other written papers after marking should be provided, particularly for those who fail. The use of a computer printout analysis would show up areas of weakness and strength and also help to eliminate ambiguous questions. A large bank of questions would minimise the hazard of students passing questions on to those in lower years.

The problem of subjective clinical assessments by consultants would be improved by officially including ward sisters and housemen; possibly their signatures, as well as the consultant's, should appear on the assessment form.

This report would not be complete without some comment on assessments in the final year, which seemed to be working well. One major disadvantage, however, was that the student was not required to learn knowledge from different disciplines at the same time, which meant that integration between the final year subjects was not as great as in the conventional system. The remedy for this is purely an administrative one, and the problem is not an inherent fault in the system of continuous assessment.

\section{Major recommendations}

In the light of the responses to our questionnaire we put forward the following recommendations for modifying the course: (1) A core of essential knowledge should be defined and outlined clearly to students and staff and then used as the basis for examinations and for defining the pass/fail border. (2) There should be more essay, project, and tutorial work and fewer formal written examinations. (3) Various types of questions should be incorporated into each exam and less reliance placed on MC questions. (4) Greater and faster feedback from staff is needed; there should be sessions to go through written papers and more discussion with essay supervisors. (5) The criteria used in clinical assessments should be defined more clearly. (6) Housemen and ward sisters should take part in assessments on the ward.

\section{Conclusions}

The system of continuous assessment at Birmingham is popular with students but should be kept under constant review so that modifications and experiments can be made. Students are fortunate in that they can put forward criticisms within the faculty structure, and this relationship with staff planners can lead to the development of an effective modern curriculum.

We thank Professors W H Trethowan and A P D Thompson for their help, Sir George Pickering for his continued encouragement of this project, and Mary Tudor-Jones and Elaine Stuffins for their constant help with the manuscript. Some of these data were presented at the Royal Society of Medicine's symposium on continuous assessment in April 1975.

\section{References}

1 Trethowan, W H, British Medical fournal, 1970, 4, 109.

2 Trethowan, W H, Medical Teacher, 1973, 2, 9.
Are the diagnoses of gonorrhea and non-specific genital infection mutually exclusive or can they co-exist?

Gonorrhoea and non-specific urethritis frequently co-exist in the same patient, in many instances the agents responsible for each being caught on the same occasion. Gonorrhoea, however, has a few day's incubation period, whereas non-specific urethritis has a longer one. The symptoms and signs of gonorrhoea, therefore, appear first and, with modern treatment, disappear rapidly in a few days. Shortly afterwards, usually about seven to 21 days later, the patient develops a new discharge from the urethra, often associated with symptoms of urethritis. Microbiological examination of the discharge shows the condition to be non-specific urethritis. Both Mycoplasma hominis of the $\mathrm{T}$-strain and Chlamydia trachomatis have been thought to be responsible for postgonococcal non-specific urethritis. It usually responds to tetracycline or oxytetracycline, at a dose of $250 \mathrm{mg}$ six hourly for 21 days. The cure rate following a single course is about $85 \%$. ${ }^{1}$ Holmes, K K, et al, fournal of the American Medical Association, 1967, 202, 467.
${ }^{2}$ Richmond, S J, Hilton, A L, and Clarke, S K R, British fournal of Venereal
Diseases, 1972, 48, 437.
Is propanidid of value in dental anaesthesia and what are its hazards?

Propanidid is an ultra short-acting intravenous anaesthetic agent which can be used alone for the extraction of one or two teeth, or as an induction agent before nitrous-oxide, oxygen, and halothane through a nasal inhaler for longer cases. The average dose is from 5 to $10 \mathrm{mg} / \mathrm{kg}$ of body weight. As an induction agent methohexitone has been found to be more satisfactory. ${ }^{1}$ The advantages are: (1) short action; (2) absence of apnoea after induction; (3) rapid recovery; (4) it may be used when barbiturates are contraindicated, as in porphyria. The disadvantages include the difficulty of injecting a rather thick oily solution when the patient's veins are small or collapsed. In addition the risk of severe anaphylactic shock is a big hazard and several instances have been reported. This may be the result of the castor oil type solvent and not the drug itself. Hence propanidid should be used only by experienced anaesthetists and where necessary resuscitation equipment is available.

1 Young, T M, Anaesthesia, 1974, 29, 614 